\title{
CORRIGENDUM
}

\section{MUC4 regulates cellular senescence in head and neck squamous cell carcinoma through p16/Rb pathway}

MA Macha ${ }^{1}$, S Rachagani ${ }^{1}$, P Pai ${ }^{1}$, S Gupta ${ }^{1}$, WM Lydiatt ${ }^{2}$, RB Smith ${ }^{2}$, SL Johansson ${ }^{3}$, SM Lele ${ }^{3}$, SS Kakar ${ }^{4}, \mathrm{H} \mathrm{Farghaly}^{4}, \mathrm{JH}_{\text {Lee }}{ }^{5}, \mathrm{~J} \mathrm{Meza}^{6}$, AK Ganti ${ }^{7}$, M Jain ${ }^{1}$ and SK Batra ${ }^{1,8,9}$

Correction to: Oncogene (2015) 34, 1698-1708; doi:10.1038/ onc.2014.102; published online 21 April 2014

The authors wish to add $\mathrm{H}$ Farghaly, originally included in the Acknowledgements, to the authorship of this article, published online 21 April 2014. Dr Farghaly was omitted from the byline at final submission due to communication impediments outside the authors' control during the manuscript review period which were shortly thereafter resolved.

The authorship should read as follows: MA Macha ${ }^{1}$, S Rachagani ${ }^{1}$, P Pai ${ }^{1}$, S Gupta ${ }^{1}$, WM Lydiatt ${ }^{2}$, RB Smith ${ }^{2}$, SL Johansson ${ }^{3}$, SM Lele ${ }^{3}$, SS Kakar ${ }^{4}, \mathrm{H}$ Farghaly ${ }^{4}$, JH Lee ${ }^{5}$, J Meza ${ }^{6}$, AK Ganti ${ }^{7}$, M Jain ${ }^{1}$ and SK Batra ${ }^{1,8,9}$. This has now been updated in both the PDF and HTML versions of the article.

${ }^{1}$ Department of Biochemistry and Molecular Biology, University of Nebraska Medical Center, Omaha, NE, USA

${ }^{2}$ Department of Otolaryngology, University of Nebraska Medical Center, Omaha, NE, USA
${ }^{3}$ Department of Pathology, University of Nebraska Medical Center, Omaha, NE, USA

${ }^{4}$ Department of Physiology and Biophysics, University of Louisville, Louisville, KY, USA

${ }^{5}$ Sanford ENT-Head and Neck Surgery, Sanford Cancer Research Center, Sioux Falls, SD, USA

${ }^{6}$ Department of Biostatistics, College of Public Health, University of Nebraska Medical Center, Omaha, NE, USA

${ }^{7}$ Department of Internal Medicine, VA Nebraska Western lowa Health Care System and University of Nebraska Medical Center, Omaha, NE, USA

${ }^{8}$ Buffett Cancer Center, University of Nebraska Medical Center, Omaha, NE, USA

${ }^{9}$ Eppley Institute for Research in Cancer and Allied Diseases, University of Nebraska Medical Center, Omaha, NE, USA 